\title{
MRI EVALUATION OF SUPRATENTORIAL TUMOURS
}

\author{
Shruti Patil1, Mahesh ${ }^{2}$, Govindaraju ${ }^{3}$ \\ ${ }^{1}$ Assistant Professor, Department of Radiology MR Medical College, Gulbarga. \\ ${ }^{2}$ Post Graduate, Department of Radiology, MR Medical College, Gulbarga. \\ ${ }^{3}$ Post Graduate, Department of Radiology, MR Medical College, Gulbarga.
}

\begin{abstract}
Brain tumours represents $1.7 \%$ of all cancers and contributes $1.8 \%$ of all cancer deaths. Of all the brain tumours $80 \%$ are supratentorial. ${ }^{1}$ Magnetic Resonance Imaging is an important modality, having higher sensitivity for detecting intracranial pathology. Multiplanar imaging is possible with MRI which helps in detection, localization and characterization of the lesion. The MRI examination has helped in early diagnosis, accurate localization of the tumour with prompt initiation of appropriate medical or surgical therapy. Recent advances like Magnetic Resonance (MR) spectroscopy, MR fluoroscopy with stereotactic guided biopsy have revolutionized the role of MRI in study of intracranial tumours.
\end{abstract}

\section{AIMS AND OBJECTIVES}

The objective of the present study is to assess diagnostic ability of MRI in characterizing various supratentorial tumours using $\mathrm{T} 1$ and $\mathrm{T} 2$ weighted and contrast enhanced image.

\section{MATERIALS AND METHODS}

The present study was conducted in the Department of Radio-diagnosis, Basaveshwar Teaching and General Hospital attached to Mahadevappa Rampure Medical College, Gulbarga, during the period of Oct 2014 to Oct 2015.

\section{Source of data}

All clinically suspected supratentorial brain tumour cases undergoing MRI at Basaveshwar Teaching and General Hospital attached to Mahadevappa Rampure Medical College, Gulbarga, are taken.

\section{Inclusion Criteria}

Cases referred for MRI with clinically suspected supratentorial brain tumours.

\section{Exclusion Criteria}

All patients having cardiac pace makers, prosthetic heart valves or any metallic orthopaedic implants.

Supratentorial pathology due to infections

Trauma or cerebrovascular accidents will be excluded.

\section{RESULTS}

The present study was conducted in the Department of Radio-diagnosis. BTGH attached to MR Medical College Gulbarga patients were studied and the observations and findings were noted as below.

In the present study,

Majority of the patients belonged to the age group of 11 to 20 years, 23 patients were males and 27 were females, males majority had glioma of low-grade variety. In females glioma followed by pituitary adenoma. Headache and vomiting most common presentations. Majority of the supratentorial tumors had intra-axial location. Mass of effect and hydrocephalus is present in majority of patients.

\section{KEYWORDS}

MRI, Supratentorial, GBM, Oligodendroglioma, Astrocytoma.

HOW TO CITE THIS ARTICLE: Patil S, Mahesh, Govindaraju. MRI evaluation of supratentorial tumours. J Evolution Med Dent Sci 2016;5(2):141-147, DOI: 10.14260/jemds/2016/34

Financial or Other, Competing Interest: None.

Submission 14-12-2015, Peer Review 15-12-2015,

Acceptance 02-01-2016, Published 06-01-2016.

Corresponding Author:

Dr. Shruti Patil,

H. No. 203, 2nd Floor

Lahoti Apartment,

Opposite Good luck Hotel,

Khubaplot,

Gulbarga-585102.

E-mail:drshrupatil@gmail.com

DOI:10.14260/jemds/2016/34

\section{INTRODUCTION}

Brain tumours represents $1.7 \%$ of all cancers and contributes $1.8 \%$ of all cancer deaths. Of which $80 \%$ are supratentorial. ${ }^{1}$ Magnetic Resonance Imaging is a new and an important modality, which has high sensitivity for detecting intracranial pathology. Multiplanar imaging is possible only with MRI, which helps in detection, localization and characterization of the lesion. The MRI examination has helped in early diagnosis, accurate localization of the tumour with prompt initiation of appropriate medical or surgical therapy. 
It helps in recognizing the type of tumour by its characteristic appearance and location. Recent advances like Magnetic Resonance (MR) spectroscopy, MR fluoroscopy with stereotactic-guided biopsy have revolutionized the role of MRI in study of intracranial tumours.

\section{AIMS AND OBJECTIVES}

The objective of the present study is to assess diagnostic ability of MRI in characterizing various supratentorial tumours using T1 and T2 weighted and contrast enhanced image.

\section{MATERIALS AND METHODS}

The present study was conducted in the Department of Radiodiagnosis, BTGH attached to MRMC, Gulbarga, during the period of Oct 2014 to Oct 2015.

Fifty cases of supratentorial brain tumour cases were included.

\section{Inclusion Criteria}

Cases referred for MRI with clinically suspected supratentorial brain tumours.

\section{Exclusion Criteria}

All patients having cardiac pace makers, prosthetic heart valves or any metallic orthopaedic implants.

\section{Follow up}

All patients were followed up in surgery and on HPR, were compared with the MRI features, final outcome of the disease was recorded.

\section{RESULTS}

In the present study majority of the patients (11) belonged to the age group of 11 to 20 years. Among the others age ranged from 51 to 60 years (9), 41 to $50(9), 21$ to $30(8), 31$ to 40 (6), 61 to 70 (4) and 0 to $10(3)$.

In this study, 23 patients were males and 27 were females. Among the males majority (13) of the patients had glioma and 3 patients each had meningioma, pituitary adenoma and 2 benign cystic lesions. One case each of lymphoma and metastasis were noted. In females majority (9) of the patients had glioma followed by 5 patients each had pituitary adenoma and metastasis; 4 patients had meningioma, 2 patients had central neurocytoma and one each had pineal region tumour and benign cystic lesions.

In this study, higher incidence of gliomas (44\%) were noted. The other tumors noted were pituitary adenoma (16\%), meningioma (14\%), central neurocytoma (4\%), lymphoma (2\%), pineal region tumors (2\%), benign cystic lesions (6\%) and metastasis (12\%).

In this study, majority (12) of the patients with gliomas had low-grade gliomas. The others subgroups of gliomas were glioblastoma multiformae (4), high-grade glioma (3), oligodendrogliomas (2) and ependymoma (1).

In the present study, majority (60\%) of the patients had headache followed by vomiting in $44 \%$ patients. The other clinical symptoms were giddiness $(16 \%)$, visual disturbance (24\%), seizures (34\%), altered sensorium (20\%), behavioural disturbances (24\%), limb weakness (32\%) and excess hormone secretion (10\%).
In the present study, majority (68\%) of the supratentorial tumours had intra-axial location. In this study overall 23 patients had homogenous, 11 had heterogeneous and 16 had non-enhancing pattern of the tumors. Among the patients with homogenous pattern 10 patients had glioma 6 patients had meningioma and 2 patients had pituitary adenoma. In patients with heterogeneous pattern 5 patients had glioma and among the patients with non-enhancing pattern, 7 patients had glioma, 4 had pituitary adenoma and 3 had benign cystic lesions.

In this study surrounding edema was present $40 \%$ of the cases with glioma, $33.3 \%$ cases of meningioma and $100 \%$ of cases with metastasis and lymphoma. In this study incidence of mass of effect and hydrocephalus was seen in $54 \%$ of the cases with gliomas, $12.5 \%$ in pituitary adenoma, $43 \%$ in meningioma, $100 \%$ in central neurocytoma, $100 \%$ in lymphoma and pineal region tumors, and $67 \%$ in benign cystic lesions and $50 \%$ metastasis.

\begin{tabular}{|c|c|c|c|c|c|c|c|}
\hline $\begin{array}{l}\text { Supratentorial } \\
\text { Tumors }\end{array}$ & $\frac{0}{1}$ & 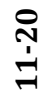 & ì & $\frac{\stackrel{P}{+}}{\dot{m}}$ & 官 & ஜ̊ & $\frac{0}{7}$ \\
\hline Glioma & 1 & 5 & 2 & 3 & 4 & 4 & 3 \\
\hline Pituitary adenoma & - & 3 & 3 & 1 & 1 & - & - \\
\hline Meningioma & - & - & 2 & 1 & 2 & 1 & 1 \\
\hline $\begin{array}{c}\text { Central } \\
\text { neurocytoma }\end{array}$ & 1 & 1 & - & - & - & - & - \\
\hline Lymphoma & - & - & - & - & - & 1 & - \\
\hline $\begin{array}{l}\text { Pineal region } \\
\text { tumors }\end{array}$ & - & 1 & - & - & - & - & - \\
\hline $\begin{array}{c}\text { Benign cystic } \\
\text { lesions }\end{array}$ & 1 & 1 & 1 & - & - & - & - \\
\hline Metastasis & - & - & - & 1 & 2 & 3 & - \\
\hline Total & 3 & 11 & 8 & 6 & 9 & 9 & 4 \\
\hline
\end{tabular}

\begin{tabular}{|c|c|c|c|}
\hline Tumors & Males & Females & Total \\
\hline Glioma & 13 & 9 & 22 \\
\hline Pituitary adenoma & 3 & 5 & 8 \\
\hline Meningioma & 3 & 4 & 7 \\
\hline Central neurocytoma & - & 2 & 2 \\
\hline Lymphoma & 1 & - & 1 \\
\hline Pineal region tumors & - & 1 & 1 \\
\hline Benign cystic lesions & 2 & 1 & 3 \\
\hline Metastasis & 1 & 5 & 6 \\
\hline $\begin{array}{r}\text { Table 2: } \\
\text { sup }\end{array}$ & $\begin{array}{l}\text { wise } \\
\text { entori }\end{array}$ & $\begin{array}{l}\text { ibution of } \\
\text { mors }\end{array}$ & \\
\hline
\end{tabular}

\begin{tabular}{|c|c|c|}
\hline Tumors & $\begin{array}{c}\text { Number of } \\
\text { Cases }\end{array}$ & Percentage \\
\hline Glioma & 22 & $44 \%$ \\
\hline Pituitary adenoma & 8 & $16 \%$ \\
\hline Meningioma & 07 & $14 \%$ \\
\hline $\begin{array}{c}\text { Central } \\
\text { neurocytoma }\end{array}$ & 02 & $4 \%$ \\
\hline Lymphoma & 02 & $4 \%$ \\
\hline Pineal region tumors & 02 & $4 \%$ \\
\hline Benign cystic lesions & 03 & $6 \%$ \\
\hline Metastasis & 06 & $12 \%$ \\
\hline Total & 50 & $100 \%$ \\
\hline
\end{tabular}




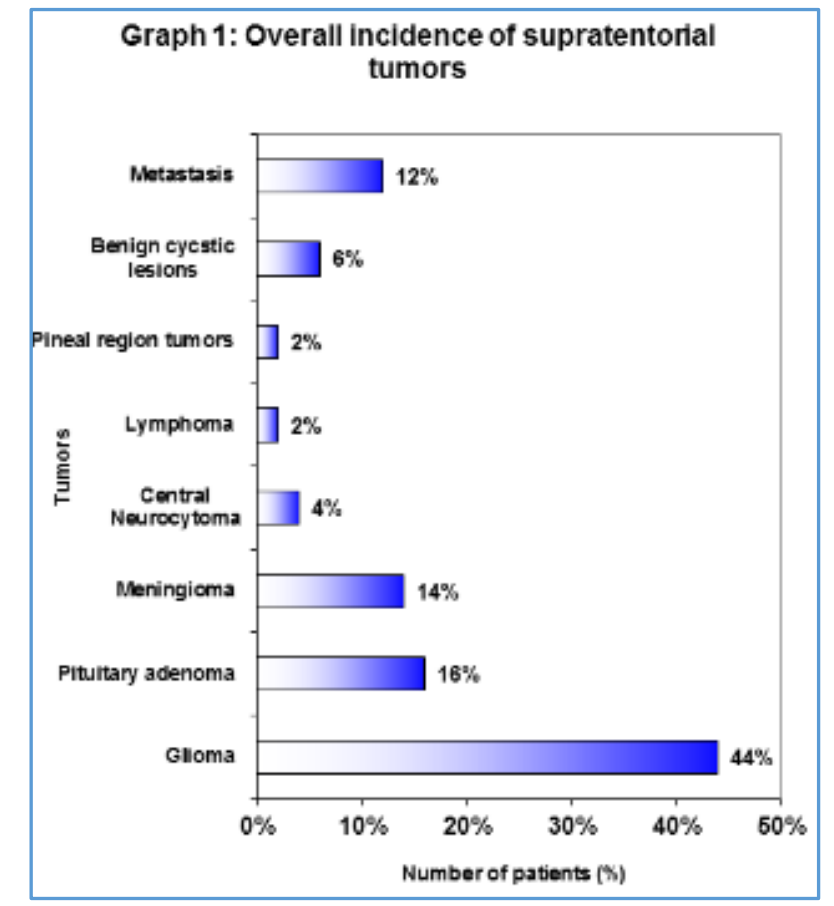

\begin{tabular}{|c|c|}
\hline Subgroups of Glioma & Number of Patients \\
\hline Low grade gliomas & 12 \\
\hline High grade gliomas (Anaplastic) & 03 \\
\hline Glioblastoma multiforme & 04 \\
\hline Oligodendroglioma & 02 \\
\hline Ependymoma & 01 \\
\hline Total & 22 \\
\hline \multicolumn{2}{|c|}{$\begin{array}{l}\text { Table 4: Distribution of subgroups } \\
\text { among the patients with Gliomas }\end{array}$} \\
\hline
\end{tabular}

\begin{tabular}{|c|c|c|}
\hline Symptoms & $\begin{array}{c}\text { Number of } \\
\text { Cases }\end{array}$ & Percentage \\
\hline Headache & 30 & $60 \%$ \\
\hline Vomiting & 22 & $44 \%$ \\
\hline Giddiness & 16 & $16 \%$ \\
\hline Visual disturbances & 12 & $24 \%$ \\
\hline Seizures & 17 & $34 \%$ \\
\hline Altered sensorium & 10 & $20 \%$ \\
\hline $\begin{array}{c}\text { Behavioural } \\
\text { disturbances }\end{array}$ & 12 & $24 \%$ \\
\hline $\begin{array}{c}\text { Weakness in the } \\
\text { limbs }\end{array}$ & 16 & $32 \%$ \\
\hline $\begin{array}{c}\text { Features of excess } \\
\text { hormone secretion }\end{array}$ & 05 & $10 \%$ \\
\hline \multicolumn{2}{|c|}{ Table 5: Symptoms of the patients } \\
with Supratentorial Tumors \\
\hline
\end{tabular}

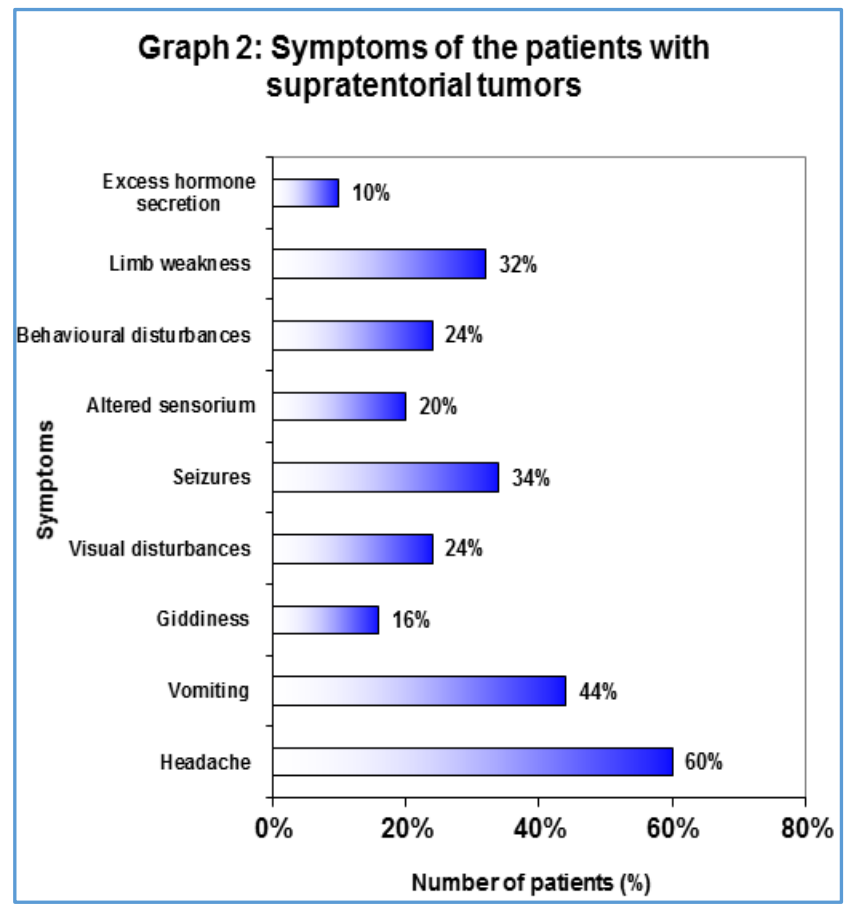

\begin{tabular}{|c|c|c|}
\hline Location & Number of cases & Percentage \\
\hline Intra axial & 34 & $68 \%$ \\
\hline Extra axial & 16 & $32 \%$ \\
\hline \multicolumn{3}{|c|}{ Table 6: Locations of Tumors } \\
\hline
\end{tabular}

\begin{tabular}{|c|c|c|c|}
\hline Tumors & Homogeneous & Heterogeneous & $\begin{array}{c}\text { Non- } \\
\text { enhancing }\end{array}$ \\
\hline Glioma & 10 & 5 & 7 \\
\hline $\begin{array}{c}\text { Pituitary } \\
\text { adenoma }\end{array}$ & 2 & 2 & 4 \\
\hline Meningioma & 6 & 1 & - \\
\hline $\begin{array}{c}\text { Central } \\
\text { neurocytoma }\end{array}$ & - & 2 & - \\
\hline Lymphoma & 1 & - & - \\
\hline $\begin{array}{c}\text { Pineal region } \\
\text { tumors }\end{array}$ & 1 & - & - \\
\hline $\begin{array}{c}\text { Benign cystic } \\
\text { lesions }\end{array}$ & - & - & 3 \\
\hline Metastasis & 3 & 1 & 2 \\
\hline Total & 23 & 11 & 16 \\
\hline \multicolumn{4}{|c|}{ Table 7: Enhancement Pattern of Tumors } \\
\hline
\end{tabular}




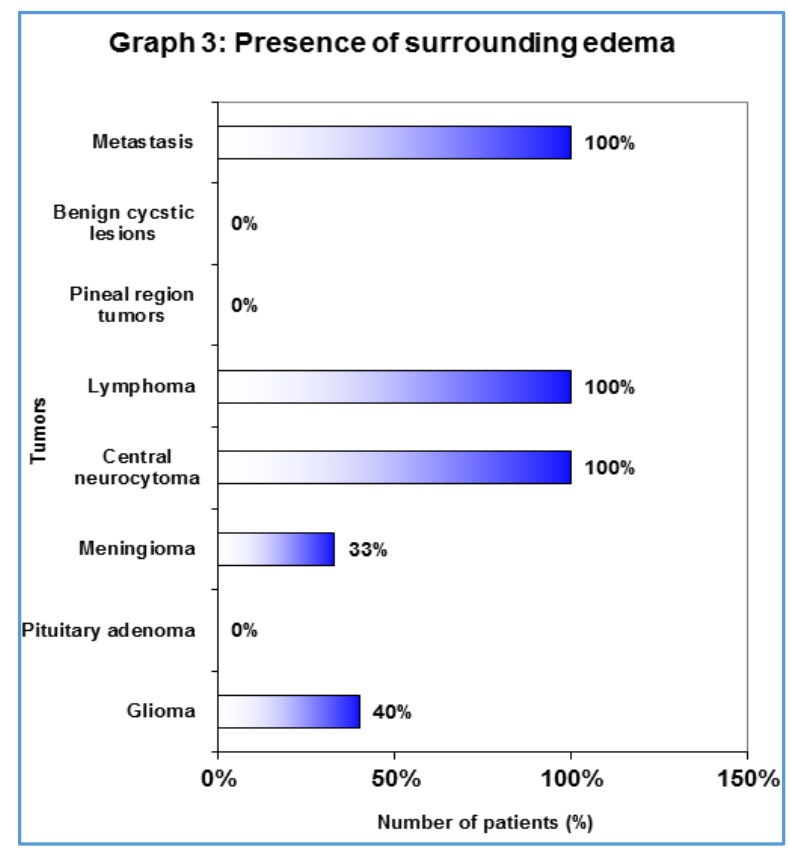

\section{DISCUSSION}

Magnetic resonance imaging is a non-invasive, reproducible and highly accurate method which demonstrates size, location configuration, extent and relationship of the lesion to the adjacent structures. By analysing the MR features of neoplasms one can have high specificity of MRI in identifying the nature of the lesion and if possible its histological type.

In this study of 50 cases with supratentorial tumors, glioma was the most common diagnosis (44\%). Others include pituitary adenoma, meningioma, lymphoma, central neurocytoma, pineal region tumors such as germinoma and pineocytoma, colloid cyst, Rathke's cleft cyst, arachnoid cyst and metastasis. Relative frequencies of intracranial tumors in various studies compared with our study. Hence, present study showed a higher incidence of gliomas, pituitary adenoma and lymphoma.

\section{Age Distribution}

The age group from 5 to 63 years, peak incidence of neoplasms was seen in third decade.

\section{Sex Distribution}

Female and male patients were 27 and 23.

\section{Clinical Features}

In our study $60 \%$ of patients came with headaches. Vomiting, giddiness, seizures, visual disturbances and hormonal imbalance were the other common symptoms. In a study by Baker et al. ${ }^{2}$ report headache, altered consciousness, personality change, cognitive disabilities, seizures, visual and gait disturbances as the common presenting complaints of the patients with brain tumour.

\section{Location}

Intra-axial tumors were clearly more common than extra-axial tumors, $68 \%$ of the tumors were intra-axial, whereas $32 \%$ of them were extra-axial. This correlated with the study by National Cancer Institute. ${ }^{2}$ which report $80 \%$ as intra-axial and $20 \%$ as extra-axial tumors.

\section{Glioma}

Gliomas are the most common primary brain tumors accounting 30-60\% of all intracranial tumors. J Ambrose and MR Gooding ${ }^{3}$ studied 366 patients with brain tumours and found that gliomas contributed to $42.3 \%$.

In 1980, Baker HL et al. ${ }^{2}$ conducted a study of 1071 cases of intracranial tumors which showed $34 \%$ of gliomas. In our study incidence of gliomas was $44 \%$.

In the present study, age of the patients ranged from first to sixth decade with maximum incidence in second and fifth, sixth decades; 13 of them were males and 9 of them were females.

\section{Astrocytomas}

They constitute 30 to $35 \%$ of all intracranial tumors and more than $75 \%$ of gliomas. ${ }^{4}$ In our study there were 22 cases of represents $86 \%$ of gliomas, out of which 12 cases were lowgrade astrocytomas, three were high-grade and four were GBM. The low-grade astrocytomas were more common in females than in males (Female:Male $=7: 5$ ).

In our study, they were common in second decade. On MR, they were relatively well defined, hypo to iso intense on T1 and hyperintense on $\mathrm{T} 2$ with very little surrounding edema, mass effect.

These findings correlated with the findings reported in literature. ${ }^{5}$ only one case had intratumoral calcification. On post-contrast studies, $30 \%$ were non-enhancing and others demonstrated mild homogenous enhancement. None of the cases had areas of hemorrhage. One case of Brainstem glioma showed cystic changes.

According to Bruce L Dean et $a .^{5}$ areas of hemorrhage and cystic ranges can be seen in low grade gliomas.

\section{Anaplastic Astrocytomas}

The mean age in our study was 50 years, whereas a study by Peter C Burger et al. $^{6}$ report 46 years as the mean age incidence.

All the cases showed heterogeneous appearance on both T1 and T2 weighted images; $66 \%$ demonstrated hyperintense signal on T1 suggestive of intratumoral hemorrhage. All the cases correlated with reported literature.5,7

\section{Glioblastoma Multiforme}

In the present study, four cases of GBM were constituted 20\% of gliomas. In a study by Timokurki et al. ${ }^{7}$ glioblastomas accounted for $37 \%$ of gliomas. Thus, our study had a lesser incidence of GBM.

In this study, there is male predominance. The mean age incidence was 54 years. Peter C Burger et al. ${ }^{6}$ studied 1265 patients with glioblastomas and found that the mean age incidence was 56 years.

In this study $75 \%$ of cases were supratentorial, out of which, 50\% crossed the midline involving corpus callosum. Bruce L Dean et al. ${ }^{5}$ studied 36 cases and found that crossing of the midline was seen in $42 \%$.

Heterogeneous appearance on both T1 and T2 was noted in all the case. Surrounding edema and mass effect was seen in majority of cases. These findings correlated with reported literature. .7 
Bruce L Dean et al. ${ }^{6}$ report tumour heterogenecity in $83 \%$ and surrounding edema in $78 \%$ of gliomas.

On post contrast studies, $50 \%$ of the cases demonstrated ring like enhancement with central hypointensity suggestive of necrosis. The enhancing ring was incomplete, irregular, thick and nodular.

According to John R Hesselink et al. ${ }^{8}$ higher grade gliomas demonstrate ring enhancing pattern with central necrosis on post Gd-DTPA scans. According to Timokurki et al. ${ }^{9}$ presence of necrosis is the hallmark of GBM.

\section{Oligodendroglioma}

In the present study, two cases of oligodendrogliomas were studied and account for fourth which correlates with the percentage reported in literature. ${ }^{10,11}$ Both the cases were in their fourth decade, which corresponded with age incidence reported in literature. ${ }^{10}$ Kenneth TS et al. ${ }^{10}$ reports that there is slight male predominance, however, in this study we found equal incidence in both sexes. They were heterogeneous and both $\mathrm{T} 1$ and $\mathrm{T} 2$ with area of calcification, edema and mass effect. The above findings correlated with literature. ${ }^{10,11,12}$

\section{Ependymoma}

In this study there was one case of ependymoma (2\%), which correlates with the reported literature.13,14 According to Gregory B Nazar et al. ${ }^{14}$ ependymomas are the third most common paediatric brain tumour and two-third are infratentorial in location. In our study, the tumour was supratentorial in location and the patient's age was 42 years. Mark K Lyons et al. ${ }^{13}$ studied 30 cases of ependymomas and found that 44 years as the median age of occurrence. The tumour was hypointense on T2 and hyperintense on T2, not enhancing on contrast with no evidence of calcification or hemorrhage. Elizabeth A Healey. ${ }^{15}$ reported irregular contrast enhancement in three out of four cases. Mark K Lyons et al. ${ }^{13}$ in his study reports that contrast enhancement was seen in $62 \%$, hydrocephalus in $66 \%$ and calcification in $28 \%$.

\section{Pituitary Adenoma}

In this study, eight cases (16\%) of pituitary adenomas were evaluated by MRI, out of which 6 were microadenomas and two cases were macroadenoma. Daniel G Schwartzberg. ${ }^{16}$ reports that reports that pituitary adenomas account for 10$20 \%$ of intracranial tumors and microadenomas are more common than macroadenomas.

In the present study, $60 \%$ of cases were females and $40 \%$ were males. $62.5 \%$ of the patients presented with symptoms due to excess hormone secretion, out of which $37.5 \%$ came with hyperprolactinemia and $25 \%$ with Cushing's syndrome. These findings correlated with reported literature. ${ }^{16}$ the peak age incidence was seen in the third decade.

In this study, on MR, $75 \%$ of the adenomas were hypointense on T1 and isointense on T2W1. A study by Walter Kucharczyck et al. ${ }^{17}$ reports hypointense signal intensity on T1 in $82 \%$ of cases.

In this study, on post-contrast studies $50 \%$ of the adenomas were non-enhancing, $25 \%$ showed early enhancement and the remaining $25 \%$ of cases shows delayed enhancement. In one series. ${ }^{17}$ convexity of superior surface was seen in $82 \%$ and displacement of stalk in $64.2 \%$. Another series. ${ }^{18}$ reports stalk deviation in $88.8 \%$ of cases.

\section{Meningiomas}

The incidence of meningiomas in our study is $14 \%$, which is less than the incidence reported in literature $(20 \%$ by Peter MB). ${ }^{19}$

In this study, meningiomas were more common in females than in males, which correlated with literature. ${ }^{19}$ According to age only one of our case was aged 27 years, rest of all cases were beyond 40 years of age.

In our study, meningiomas were located in pineal region, parasagittal, sphenoid ridge tentorium and cerebellopontine angle. According one of the patient had two meningiomas. The different locations have also been reported in literature.19,20

In this study, $85 \%$ of cases were hypointense on $\mathrm{T} 1$ and $55 \%$ were hyperintense on T2W1. 40 cases of meningiomas were studied by Allen D Elster et al. ${ }^{21}$ they report isointense signal intensity on $\mathrm{T} 1$ in $62 \%$ of cases.

A study by Marie V Spagnoli et al.22 report that on T1 56\% were isointense and 36\% were hypointense, on T2W1 52\% were isointense while $44 \%$ were hyperintense. Contrast enhancement was demonstrated in all our cases, which relates with literature. .,19 $^{4}$

Calcification was seen as areas of low signal intensity in all the pulse sequences. It was demonstrated in $28.5 \%$ of case. Allen D Elster et al. ${ }^{21}$ reports calcification in $12.5 \%$ cases. Hence, our study showed a higher incidence of calcification in meningiomas.

Features of extra-axial mass lesion like "dural tail" was seen in $43 \%$ of cases. Enhancement of the dura was demonstrated in $72 \%$ of cases in a study by Shigeki Aoki et al. ${ }^{23}$ Therefore, our study showed a lesser incidence of "dural tail" sign.

\section{Lymphoma}

One case of lymphoma were studied in this study. Elderly HIV negative patients.

The tumour was seen in parasagittal right parietal lobe in periventricular white matter. Case demonstrated dense and homogeneous contrast enhancement. The above findings correlated with the reported literature..$^{24,25}$

Bernhard WS et al. ${ }^{24}$ studied 10 cases and opine that hypointense signal on $\mathrm{T} 1$ and hyperintense signal intensity on T2 with little mass effect as the commonest MR appearance of lymphomas. In our study both the cases were hypointense on $\mathrm{T} 1$ and hyperintense on T2 with very little mass effect. They also report that $75 \%$ of cases of lymphomas in non-AIDS patients were measuring more than two centimetres.

\section{Central Neurocytoma}

The incidence of central neurocytoma in our study is $4 \%$ which is higher than the percentage reported in literature.

According to Leenstra JL et al. ${ }^{26}$ central neurocytoma account for less than $1 \%(0.25 \%-0.5 \%)$ of all intracranial tumors. The peak age incidence in our study is in the $20-40$ years of age).

In this study cases were males and lateral ventricles around foramen of Monro was the commonest location, which correlated with literature. $26,27,28$

All our cases were mild-moderate heterogeneous enhancement, well defined masses, isointense to grey matter on T1, hyperintense on T2W1 and numerous cystic areas (bubbly appearance). These findings correlated with reported literature. ${ }^{28}$ 


\section{Pineal Region Tumors}

One cases of pineal region tumour, which is Pineocytoma. According to Harol J Hoffman et al. ${ }^{29}$ the peak incidence of Germinoma is during the second decade of life. On MRI, the tumour was iso-intense on both T1 and T2W1, enhancing on contrast with mass effect and hydrocephalus. These findings correlated with reported literature. ${ }^{29,30}$

Pineocytoma was detected in 20-year-old female, which was hypointense on T1 and hyperintense on T2 and showed heterogeneous contrast by Maria V Chiechi et al. ${ }^{30}$ reports a high incidence of calcification in Pineocytomas.

\section{Colloid cyst}

One case of colloid cyst was evaluated in our study, which was located at foramen of Monro.

George Morrison et al. ${ }^{31}$ studied 73 cases of intraventricular mass lesions and found that colloid cysts are the second most common intra-ventricular tumors, which was exclusively confined to the third ventricle at the foramen of Monro.

In our case, the colloid cyst was well defined, spherical in shape with central hyperintensity and peripheral hypointense signal on T1 and central hypointensity and peripheral hyperintense signal on T2W1. It was associated with dilatation of the lateral ventricles. In the literature several studies. ${ }^{32,33}$ report a variable appearance of colloid cysts on MRI.

\section{Rathke's Cleft Cyst}

This study had one case of Rathke's cleft cyst, which was incidentally detected in patients. It was a well-defined sellar mass which shoed hyperintense signal on all pulse sequences. There was mild superior displacement of optic chiasma.

MF Naylor et al. ${ }^{34}$ studied 23 cases of Rathke's cleft cysts and report a variable signal intensity on MR images. They also opine that this is due to the variation in the protein content of the cysts as well as to the presence of blood products, cholesterol and mucopolysaccharides.

\section{Arachnoid Cyst}

One case of arachnoid cyst was diagnosed in a 22-year-old who presented with a single episode of seizures.

A study by Knut Wester. ${ }^{35}$ reports that middle cranial fossa arachnoid cysts occur more commonly in males and on the left side. In our study the arachnoid cyst was situated in the right side. On MR the arachnoid cyst showed signal intensity similar to the CSF on all pulse sequences, which correlated with the reported literature. ${ }^{36,37}$

\section{Metastasis}

Six cases of intracranial metastasis studied were detected by CT scan, MRI is less frequently requested for detecting metastasis. Four patients are known cases of carcinoma breast who had multiple metastasis both in the supra- and intratentorial regions with surrounding edema and mass effect.

In the reported literature. ${ }^{37,38}$ carcinoma breast was the second most common malignancy to metastasize to brain. In our patient, multiple metastasis were detected in $\mathrm{T} 1$ and $\mathrm{T} 2$ weighed images.
According to WTC Yuh et al. ${ }^{39}$ who studied 45 cases of metastasis reports that high contrast dose $(0.3 \mathrm{mmol} / \mathrm{kg}) \mathrm{MRI}$ studies to be more effective in detection of lesions less than $10 \mathrm{~mm}$.

\section{Histopathological Correlation}

In our study out of 50 patients, 46 patients were operated accounting for $92 \%$ of cases. Four cases were managed conservatively accounting for $8 \%$ of cases.

Out of 46 operated cases, 42 cases are histopathologically correlated and 4 case are not correlated, out of which 2 cases are given as low-grade astrocytoma are turned up into high grade, one case which was given as high grade turned up into low grade and one case which was given as metastasis turned up into primary brain tumour. ${ }^{40}$

\section{CONCLUSION}

Magnetic resonance imaging scan of brain was performed in 50 patients with supratentorial tumours. Twenty eight (27 that is 54\%) patients were females and $23(46 \%)$ were males, showing female predominance.

Patient in Pediatrics age group (below the age of 18 years) accounted for only eight cases (16\%) and the adult population was $42(84 \%)$ cases.

The commonest supratentorial fossa tumour was glioma.

The commonest intra-axial tumours were gliomas (46\%), while the commonest extra-axial tumours were menigiomas (14\%).

Multiplanar capability of MRI was helpful in identifying the precise anatomic location and the exact extent of the tumours. On post contrast images there was a clear definition of the size, margins, and nature of the tumour and it also improved the differentiation between the tumour and surrounding edema.

The major limitation of MRI in our study was its inability to accurately identify the foci and calcification within the tumour.

\section{BIBLIOGRAPHY}

1. Kornienko VN, Pronin IN. Diagnostic Neuroradiology. Springer Verlag. (2009) ISBN:3540756523.

2. Yuh WT, Engelhen JD, Muhonen MG, Magr NA, Fisher DJ, Ehrhardt JC. Experience with high dose gadolinium MR imaging in the evaluation of brain metastases. Am J Neuroradiol 1992;13:335-45.

3. Baker HL, Wayne H, Campbell KL. National cancer institute study. Evaluation of computed tomography in the diagnosis of intracranial neoplasms. Radiology 1980;136:91-6.

4. Osborn AG. Brain tumours and tumour like processes. Diagnostic neuroradiology. $1^{\text {st }} \mathrm{ed}$, St. Louis: Mosby Year Book; 1994;529-64.

5. Ambrose J, Gooding MR, Richardson AE. An assessment of the accuracy of computerized transverse axial scanning (EMI scanner) in the diagnosis of intracranial tumour. Brain 1975;98:569-82.

6. Dean BL, Drayer BP, Bird CR, Flom RA, Hodak JA, Coons $\mathrm{SW}$, et al. Gliomas. Classification with MR imaging. Radiology 1990;174:411-5.

7. Burger PC, Voger FS, Green SB, et al. Glioblastoma multiforme and anaplastic astrocytoma. Pathological criteria and prognostic implications. Cancer 1985;56:1106-11. 
8. Hessenlink JR, Press GA. MR contrast enhancement of intracranial lesions with Gd-DTPA. Radiol Clin North Am 1988;26(4):473-487.

9. Kurki T, Lundbom N, Kalimo H, et al. MR classification of brain gliomas. Value of magnetization transfer and conventional imaging Magnetic Resonance Imaging 1995; 13(4): 501-11.

10. Shimizu KT, Tran LM, Mark RJ, et al. Management of oligodendrogliomas. Radiology 1993;186:569-72.

11. Lee YY, Van Tassel. Intracranial oligodendrogliomas imaging findings in 35 untreated cases. Am J Neuroradiol 1989;10:119-27.

12. Holland BA, Kucharcyzk W, Brant Zawadzki M, et al. MR imaging of calcified intracranial lesions. Radiology 1985;155:353-6.

13. Lyons M, Kelly PJ. Posterior fossa ependymomas. Report of 30 cases and review of the literature. Neurosurgery 1991;28:659-65.

14. Azar GB, Hoffman HJ, Becker LE, et al. Infratentorial ependymomas in childhood prognostic factors and treatment. J Neurosurgery 1990;72:408-17.

15. Healey EA, Barnes PD, Kupsky WJ, Scoff RM, Sallan SF, Black PM, et al. The prognostic significance of postoperative residual tumour in ependymoma. Neurosurgery 1991;28:666-72.

16. Schwartzberg DG. Imaging of pituitary gland tumours. Seminars in US CT and MRI 1992;13(3):207-23.

17. Kucharozyk W, Davis DO, Kelly WM, Sze G, Norman D, Newton TH. Pituitary adenomas. High-resolution MR imaging at 1.5 T. Radiology 1986;161:761-5.

18. Peck WW, Dillion WP, Nomran D, et al. High resolution MR imaging of pituitary microadenomas at $1.5 \mathrm{~T}$ Experience with Cushing's disease. Am J Roentegenol 1989;152:145-51.

19. Black PM. Meningiomas. Neurosurgery 1993;32:643-57.

20. Inamusa T, Nashio S, Takeshita I, et al. Peritumoral brain edema in meningiomas. Influence of vascular supply on its development. Neurosurgery 1992;31:179-85.

21. Elster AD, Challa VR, Gilbert TH, et al. Meningiomas MR and histopathologic features. Radiology 1989;170:85762.

22. Spagnoli MV, Goldberg HI, Grossman RI, Bilaniuk LT, Gomori JM, Hackney DB, et al. Intracranial meningiomas: high field MR imaging. Radiology 1986;161(2):369-75.

23. Aoki S, Sasaki Y, Machida T, et al. Contrast enhanced MR images in patients with meningioma importance of enhancement of dura adjacent to the tumour. Am J Neuroradiology 1990;11:935-8.

24. Schwaighofer BW, Hesselink JR, Press GA, Wolf RL, Healy ME, Berthoty DP. Primary intracranial CNS lymphoma. MR manifestations. AJNR Am J Neuroradiol 1989; 10:725-9.
25. Roman-Goldstein SM, Goldman DL, Howieson J. MR in primary CNS lymphoma in immunologically normal patients. AJNR Am J Neuroradiol 1992;13:1207-13.

26. Koeller KK, Sandberg GD. From the archives of the AFIP. Cerebral intraventricular neoplasms: radiologicpathologic correlation. Radiographics. 22(6):1473-505.

27. Tampieri D, Melanson D, Ethier R. MR imaging of epidermoid cysts. Am J Roentegenology 1989;10:351-6.

28. Wilms G, Marchal G, Van Hecke P. Colloid cysts of the third ventricle. MR findings. J Comput Assist Tomography 1990;14:527-31.

29. Hoffman HJ, Otsubo H, Hendrick B, et al. Intracranial germ cell tumours in children. J Neurosurg 1991;74:54551.

30. Chiechi MV, Smirniotopoulos JG, Mena H. Pineal parenchymal tumours. CT and MR features. J Comp Assist Tomogr 1995;19:509-17.

31. Wilms G, Marchal G, Van Hecke P. Colloid cysts of the third ventricle. MR findings. J Comput Assist Tomography 1990;14:527-31.

32. Tampieri D, Melanson D, Ethier R. MR imaging of epidermoid cysts. Am J Roentegenology 1989;10:351-6.

33. Morrison G, Sobel DF, Kelley WM, et al. Intraventricular mass lesions. Radiology 1984;153:435-42.

34. Naylor MF, Scheithauer BW, Forbes GS, et al. Rathke cleft cyst CT, MR and pathology of 23 cases. J Computer Assist Tomography 1995;19:853-9.

35. Wester K. Gender distribution and sidedness of middle fossa arachnoid cysts. A review of cases diagnosed with computed imaging. Neurosurgery 1992;31(5):940-3.

36. Ciricillo SF, Cogen $\mathrm{PH}$, Harsh GR, et al. Intracranial arachnoid cysts in children. A comparison of the effects of fenestration and shunting. J Neurosurgery 1991;74:230-5.

37. Harsh GR, Edwards MSB, Wilson CB. Intracranial arachnoid cysts in children. J Neurosurgery 1986;64:835-42.

38. Powers JM, Horoupian DS. CNS tumors. In: Ivan Damjanov, James Linder (Edition) Andersons pathology. 10 ed, St. Louis: Mosby Year Book; 1996;2746-65.

39. Yuh WTC, Tali ET, Nguyen HD, et al. The effect of contrast dose, imaging time and lesion size in the MR detection of intracerebral metastasis. Am J Roentegenology 1995;16:373-80.

40. Ishtiaq A Chishty, Muhammad Zafar Rafique, et al. Characterization and histopathological correlation of primary intra-axial brain glioma. JLUMHS May-August 2010; Vol: 09 No. 02. 